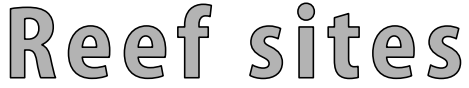

\section{The use of tools by wrasses (Labridae)}

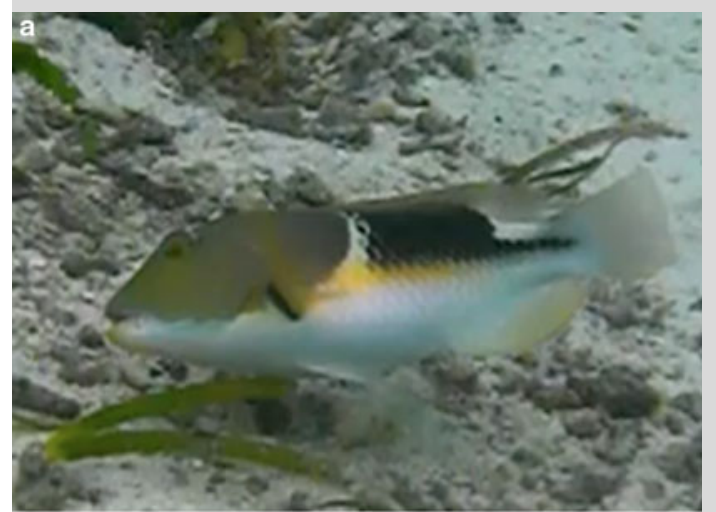

Recently, Jones et al. (2011) described the use of a rock as an anvil to crush a bivalve by a wrasse, the blackspot tuskfish, Choerodon schoenleinii.

They concluded by underscoring the importance of comparative studies on tool use in fishes. Two similar occasions of tool use were previously described for other wrasses (Labridae). In Florida, Coyer (1995) observed a yellowhead wrasse, Halichoeres garnoti. Pasko (2010) observed a sixbar wrasse, Thalassoma hardwicke, in an aquarium setting. Here, we describe a fourth instance by yet another wrasse, the orange-dotted tuskfish,

Choerodon anchorago (Fig. 1).

On July 12, 2009, at 10:30 h in Palau, in 4 feet of water, an individual C. anchorago was observed cracking bivalves using a rock as anvil. After two such events, we started filming the behavior, which was

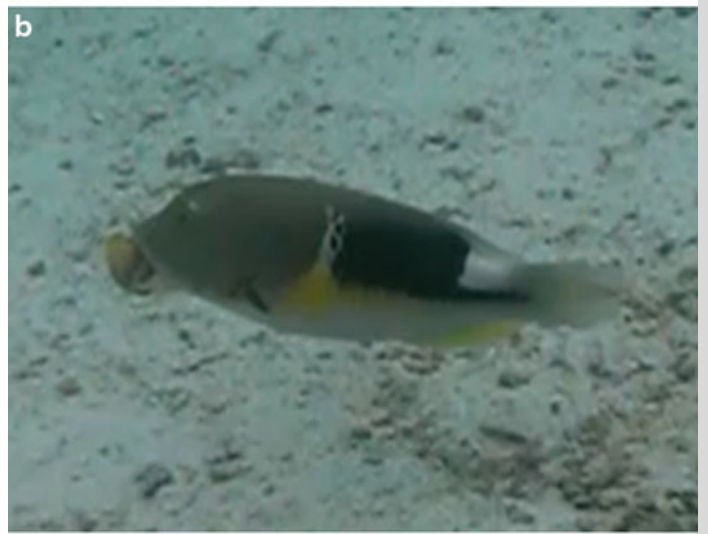
repeated a third time (see Electronic Supplementary Material). Each event lasted less than $5 \mathrm{~min}$, for a total observation time of approximately $20 \mathrm{~min}$. The fish first dug out the bivalve by fanning sand with its pectoral fin and then took the mollusk to a rock, or coral head, where it was crushed in a similar way to what has been described for $C$. schoenleinii.

The use of rock as an anvil has now been described from different places in three genera of wrasses, the ancestral Choerodon, and the more derived Halichoeres and Thalassoma, which span the majority of the evolutionary history of wrasses (50 million years, Cowman et al. 2009). All observations were similar in both the use of a rock as an anvil to open or reduce the size of a bivalve to making it edible and the sideways movement of the head associated with it. The similarity of the behaviors suggests that either they emerged independently or they correspond to a deep-seated behavioral trait. If this were the case, we predict that other wrasses are likely to also use these forms of tools. The presence or absence of such a behavior in other groups of fishes will determine whether the use of a rock as an anvil is unique to wrasses or whether it can be generalized to other groups of fishes.

\section{References}

Cowman PF, Bellwood DR, van Herwerden L (2009) Dating the evolutionary origins of wrasse lineages (Labridae) and the rise of trophic novelty on coral reefs. Mol Phylogenet Evol 52:621-631

Coyer JA (1995) Use of a rock as an anvil for breaking scallops by the yellowhead wrasse Halichoeres garnoti (Labridae). Bull Mar Sci 57:548-549

Jones AM, Brown C, Gardner S (2011) Tool use in the tuskfish Choerodon schoenleinii? Coral Reefs (in press). doi:10.1007/s00338-011-0790-y

Fig. 1 Series of three photographs (see movie in Electronic Supplementary Materials) of an orange-dotted tuskfish, Choerodon anchorago. The fish fans sand to unearth the bivalve (a), takes it into its mouth, swims approximately $5 \mathrm{~m}$ to a rock (b), and crushes the mollusk against it (c)

Pasko $Ł$ (2010) Tool-like behavior in the sixbar wrasse, Thalassoma hardwicke (Bennett, 1830). Zoo Biol 29:767-773

Electronic supplementary material The online version of this article (doi:10.1007/s00338-011-0823-6) contains supplementary material, which is available to authorized users.

G. Bernardi $(\bowtie)$

Department of Ecology and Evolutionary Biology, University of California Santa Cruz,

100 Shaffer Road, Santa Cruz, CA 95060, USA

e-mail: bernardi@ucsc.edu

Received: 19 July 2011 / Accepted: 6 September 2011 / Published online: 20 September 2011

Coral Reefs (2012) 31:39

(C) Springer-Verlag 2011 DOI 10.1007/s00338-011-0823-6 